\title{
POPULISTIČKI ODGOVOR NA DEMOKRATSKI DEFICIT
}

\author{
Mira Bogdanović \\ Zagreb
}

\begin{abstract}
SAŽETAK
Novija literatura o populizmu uglavnom se koncentrira na nedemokratski ili antidemokratski potencijal populizma. Inspiracija i argumentacija je u pravilu sa stajališta liberalne demokracije. Drugim riječima, ideološka i obranaška. Ali novi populizam dijeli nešto s liberalizmom. To je neprijateljstvo prema državi. Populizam ne postoji. Postoje samo populizmi. Svaki je populizam sui generis, situiran u konkretne povijesne okolnosti i odgovor na njih. Studije slučaja su na dnevnom redu, a iz njih se mnogo može naučiti. Tako povijesni pogled na stari populizam pokazuje naizgled paradoksalan rezultat: tradicija populizma u, na primjer, Argentini, vodila je demokratizaciji u liberalnom smislu.Novi populizam u Zapadnoj Europi, kako istraživači u raznim zemljama argumentiraju, reakcija je na krizu demokratskog ustroja zbog otuđenosti političkih kartela elita od potreba i interesa društvenih slojeva ugroženih novim formama modernizacije. Kako ovo nezadovoljstvo kanalizirati u forme koje će očuvati bit demokracije, pluralizma i tolerancije pitanje je sad. Na kraju krajeva, načelo one man, one vote obvezuje. Autori koji mimo ideoloških sudova ovome problemu posvećuju dužnu pažnju, inzistiraju na potrebi integracije osujećenih dijelova političke zajednice u politički sustav. Nizozemski politolog Cas Mudde zgodnom je dosjetkom stavio prst na bolno mjesto: populizam je neliberalni demokratski odgovor na nedemokratski liberalizam. Jaz između dobitnika i gubitnika društvenih promjena trebalo bi premostiti politikom koja gubitnike ne gura u naručje onih formi populizma koje graniče s fašizmom. Inkorporacija populističkih toposa u etablirane političke partije i njihove kartele nije lijek, već je to uzmak pred navalom populističke stihije. Problem ostaje otvoren, kako dalje? Represija, tolerancija, pluralizam ili nešto treće?
\end{abstract}

KLJUČNE RIJEČI: populizam sui generis, stranački karteli, nedemokratski liberalizam, demokracija

Populizam je izgleda nemoguće definirati bez zaleđine ideološke pozicije onoga koji definira. Tako je liberalni pogled na populizam vladajući pristup. Ideološka strast će se prerušiti u znanstveni pristup pa izvršiti nasilje nad povijesnim činjenicama. Lijep je primjer za to rad Nebojše Popova iz 1992. 
gdje on, newborn liberal, povlači ravnu crtu između ljubitelja nacizma Dimitrija Ljotića i Slobodana Miloševića. Dakle, dva totalitarizma. Izvlačeći frazu narod u prvi plan, on će izbrisati sve razlike i proglasiti populističkim čak partizansko geslo „Smrt fašizmu - Sloboda narodu“. Kako Milošević, tako i oporba njegovu režimu je, prema Popovu, populizam. Jedino liberalna demokracija - kao norma - to nije. Da bi došao na ovu poziciju, Popov je prevalio dugačak ideološki put. Radikalni praxisovski ljevičar, žrtva sa sedam drugih kolega očišćenih iz Partije s Filozofskog fakulteta, godinama će kod partijskih foruma osporavati njihovu odluku, da bi našao mir u zagovaranju totalne privatizacije i uklanjanju svakog traga kolektivizma kao cilja tranzicije. Za tzv. građansku Srbiju karakteristično je oštro razdvajanje liberalne elite i populističke rulje (Popov 1993). ${ }^{1}$

Dubravka Stojanović, na međunarodnoj konferenciji u Sarajevu travnja 2017. godine, pod naslovom Srbija - avangarda populizma, piše: „Konačno jedna stvar u kojoj je Balkan bio u prednosti u odnosu na Evropu! Populizam. Od kad se reč pojavila u masovnoj upotrebi, spremam se da Srbiju, a možda i ceo Balkan, proglasim avangardom populizma. Da pokažem da i mi u nečemu prednjačimo, da i mi možemo nekome da objasnimo šta im se sprema, šta vi, latecomersi, treba da očekujete, kako da postupate! Kakav moćan osećaj!" (Stojanović, 2017) Za nju je populizam srpski radikalizam Svetozara Markovića, Nikole Pašića, realni socijalizam, samoupravljanje, režimi Miloševića i Vučića. Izgleda da do avangardne Srbije nije doprla vijest da populizam cvijeta u uzornim liberalnim demokracijama. Tamo postoji (neo)liberalni autohtoni populizam - npr. u Nizozemskoj, Italiji, Norveškoj. Usvojivši bez kritičke distance opus Latinke Perović, prema kojem se Srbija od 1878. nadalje vrti u krugu kolektivizma, egalitarizma, siromaštva, tradicionalizma, Stojanović se dohvatila pomodne fraze „populizam” kao kategorije koja opisuje oko dvjesto godina srpske i balkanske povijesti, te zamijenila analitički pristup jednom formulom populizam. Tako ona podsjeća na Molièreovog junaka Monsieura Jourdainea koji odjednom otkriva da je cijeli život govorio u prozi.

I srbijanski su se libertarijanci oglasili na temu populizma. Njima je trn u oku država socijalnog staranja, velika javna potrošnja, oni dovode u blisku vezu Rooseveltov New Deal s fašizmom, a uvode pojam totalnog populizma koji je istovremeni napad na sve elemente postojećeg liberalnog sistema. Primjeri su boljševizam i nacizam (Nikolić 2017, 7-8). Oni su samo eksplicitno rekli ono što su Popov, Stojanović i mnogi drugi tek natuknuli.

1 Videti također njegovu knjigu dokumenata o borbi praxisovaca za povratak u krilo Partije Contra fatum: Slučaj grupe profesora Filozofskog fakulteta u Beogradu 1968-1988 (Popov, 1989). O liberalnom obratu Nebojše Popova pisala sam opširnije na drugom mjestu (Bogdanović 2015). 
Pionirski zbornik Ernesta Gellnera i Ghįte Ionescua (Londonska konferencija 1967) ima za povod također ideološku zabrinutost zbog već tad opaženog širenja populizma u antikolonijalnim revolucijama, komunističkom svijetu, ali i u liberalnim demokracijama. Konferencija nije puno pridonijela razjašnjavanju problema, a ista pojmovna zbrka vlada i danas: da li se radi o ideologiji(ama), pokretu ili oboma, mentalitetu koji se stalno ponovno vraća u raznim povijesnim ili geografskim kontekstima, jednom sindromu, da li je to fenomen političke psihologije (ili patologije koja se ispoljava u maniji gonjenja), ili pak osobena forma negativizma? I mnoga druga još uvijek otvorena pitanja (Ionescu i Gellner 1970). Danas je situacija drugačija: populizam je na usnama svakoga tko se bavi politikom. Preostaje jedan kameleonski politički fenomen, kojemu je teško naći zajednički nazivnik a da se njegova bit sui generis ne ošteti i promaši sama bit populizma. Populizam nema svoju Kominternu koja propisuje ideologiju i ustroj pokreta.

Cas Mudde i Cristóbal Kaltwasser (2017) nastoje izbjeći fetišizam idealizirane liberalne demokracije u kojoj je populizam strano tijelo karakterističan za navedene predstavnike ideološkog liberalizma. Ovi autori populizam situiraju baš u kontekst liberalne demokracije, a ovaj izbor je određen prije empirijom i teorijom nego ideologijom. Teorijski je najfundamentalnije jukstapozicionirati populizam i liberalnu demokraciju, a ne demokraciju kao takvu ili bilo kakav drugi model demokracije. Empirijski najrelevantniji populistički akteri vrše mobilizaciju unutar liberalno-demokratskog okvira, tj. sustava koji već jest ili nastoji postati liberalnom demokracijom. Oni ne misle da je liberalna demokracija savršena, niti da je bilo koji drugi sistem po definiciji nedemokratski. A njihov je pristup, uvjereni su, primjenljiv i izvan toga konteksta (Mudde i Kaltwasser 2017, 1-2). Oni se pitaju da li je (i kakva je) ideologija populizam da bi analizirali njegove konkretne pojavne forme. Polazište im je da je populizam, za razliku od razvijenih, koherentnih ideologija, poput socijalizma, fašizma i liberalizma, rasplinuta ideologija koja se lako dade prilijepiti uz razvijene ideološke sustave, te tako proizvesti lijevi ili desni pokret. Pozitivno je u ovoj viziji što populizam kao rudimentarnu ideologiju oštro razlikuju od fašizma i socijalizma, koji su za ideološke obranaše isto. Jovo Bakić će njihovu poziciju sažeti mišlju da je populizam u biti „borbeni pojam koji koriste konzervativni liberali i njima skloni politikolozi, sumnjičavi prema ideji narodnog suvereniteta, tj. radikalnoj demokratiji i savremenoj levici. Njime se izražava negativan i potcenjivački odnos prema populusu, $\mathrm{tj}$. narodu u smislu svetine jer populista isključivo eksploatiše niske strasti, neostvarive želje, predrasude i strahove društveno neizdiferencirane mase, radilo se o nacionalnim, socijalnim, ksenofobičnim ili nekim drugim" (Bakić 2013). Zato je umjesno upitati se je li Vučić populist. Ako je 
po rutinskoj teoriji narod uzvišen, onda on nije populist. Prije bi se moglo reći da je liberal, jer provodi neoliberalne mjere, a istim pogrdama kao Nebojša Popov i Latinka Perović časti narod (Bogdanović 2016). ${ }^{2}$

U pravu su autori kad u populizmu traže ono što je bit isključivo populizma, eliminiranjem sastojaka koje on dijeli s drugim političkim projektima. Dakle, što je čist populizam, bez miješanja sa strane? Da li je populizam „tanka” ideologija koja univerzalno vrijedi, kako misle Mudde i Kaltwasser, ili je koncept ideologije nekoristan za shvaćanje populizma, kako misli Bakić, koji poistovjećuje populizam i demagogiju? I to pridonosi konfuziji. Tu nailazimo na nekoliko problema. Kad sve primjese - klijentelizam, mržnju prema elitama, karizmu, demagogiju, mobilizaciju, manipulaciju, nacionalizam, antisemitizam, ksenofobiju, rasizam, eliminiramo, što onda preostaje? Ipak populizam sui generis. Jer, što imaju zajedničkoga povijesne forme s današnjim formama populizma? Već su i stare forme, koje se navode i prikazuju u pregledima nespojive. Na primjer: narodnjaštvo u carskoj Rusiji i američki populizam krajem 19. stoljeća nemaju ništa zajedničkog, osim ruske i engleske riječi koja znači narod. Dakle, postoji masa autohtonih populizama kad se situacija za njihov uzgoj pojavi. Što ima npr. Lega Nord s norveškim populizmom? Mislim da je opravdano rusko narodnjaštvo sasvim brisati sa popisa, jer je populizam nešto što dolazi odozdo, na manipulativni način koristi nezadovoljstvo, prikraćenost i izopćenost iz kartelizirane politike. Jest da je za ruske narodnjake narod dobar, ali se on nije odazvao na krik intelektualnih misionara, već su ih ruski kmetovi denuncirali tajnoj policiji. Traženje zajedničkih karakteristika populizma s ciljem otkrivanja zajedničke ideologije uzaludan je posao. Nužno za adekvatan pristup populizmu je uvijek imati na umu povijesni kontekst u konkretnim sredinama. Zato su povijesne paralele posve sterilne. Važnije je istraživanje zajedničkih crta političke scene nastupom neoliberalne ideološke hegemonije. Gubitak moći ranijih političkih formacija, topljenje vjernosti svojoj tradicionalnoj partiji, porast broja dezorijentiranih lutajućih glasača.

Referendum je važan sastojak populističke, uvjetno rečeno, ideologije. Ali zrelo odlučivanje, kako piše Ivan Janković u abolicionističkoj knjizi o smrtnoj kazni, nije lako: „Javno mnjenje čiji bismo glas bili skloni da poslušamo mora da bude obavešteno i prosvećeno. Ako neko podržava smrtnu kaznu zbog njenog preventivnog dejstva, on mora biti obavešten o rezultatima naučnih istraživanja o tom pitanju. S druge strane, ne može se uvažiti odlučivanje zasnovano na predrasudama ili na moralnim sudovima koji su ispod dostignutih civilizacijskih normi” (Janković 1985, 46). Ovaj načelni stav vrijedi za sva pitanja na koja populizam u praksi nudi

2 O političkoj antropologiji u djelu Latinke Perović opširno sam pisala u: Bogdanović, Mira (2016). 
svoje rješenje. Komu je u interesu da manipulira neobaviještenim i neprosvijetljenim pukom?

Dosad sam jak naglasak stavila na negativnu i neutralnu percepciju populizma. Manje je u cirkulaciji njegova pozitivna percepcija. Noam Chomsky i Jakob Augstein s ljevice analiziraju populizam. Chomsky konstatira da su tradicionalne političke institucije u zadnje vrijeme „ugrožene naletom nečega što se naziva 'populizmom'. Taj termin se koristi prilično neodređeno da bi se opisao talas nezadovoljstva, besa i prezira prema institucijama koje su bile na čelu neoliberalne ofanzive, što je dovelo do stagnacije za većinu i spektakularne koncentracije bogatstva u rukama malobrojnih". Sve je prepušteno tržištu kao najučinkovitijem zaštitniku osobnih sloboda, a korporacije na koje glasači nemaju nikakav utjecaj vladaju ekonomijom. Tako u SAD, ali: „Demokratija se još direktnije suzbija u Evropi: tamo je donošenje ključnih odluka prepušteno trima institucijama - MMF, ECB i EK - čiji predstavnici ne izlaze na izbore, a račune polažu bankama i kreditorima iz severnih zemalja." Posljedica je atomizacija društva, postoje samo pojedinci usporedivi s vrećom krumpira, a alternativu „lažnom” Trumpovom populizmu Chomsky vidi u nastanku ,jedne istinski 'narodne partije' čiji je birački blok stvarno biračko telo zemlje, sa načelima i vrednostima koje zavređuju poštovanje" (Barsamian 2017). Slično tomu Jakob Augstein: „Populizam sam po sebi nije loš. Loš je samo loš populizam. (...) Uspeh desnog populizma je veliki zato što se odnosi na realne probleme" (Eigenmann 2017). Augstein drži da je svaka politika populistička djelatnost te da desnom populizmu treba suprotstaviti lijevi. Takav bi populizam trebao podvrgnuti kritici vladajući model ekonomije, dovesti do „emancipacije od ekonomije koja ljudima ukida mogućnost izbora i dostojanstvo”. On govori: „Levica se politički organizuje protiv jakih, a desnica protiv slabih" (Eigenmann 2017). Populističko je u lijevom populizmu direktno obraćanje građanima s prijedlogom novog društvenog ugovora. Tu sličnost prestaje.

Ako narodnu suverenost uzmemo za samu bit liberalne demokracije, onda je populizam legitimna pojava, ali je i bezobrazno neželjeno dijete kojega se otac odriče. A što je alternativa? Vladavina elite, kojoj nije u interesu da neodgojeni pubertetlija kvari sreću. Pa zar elite u percepciji naroda nisu i pokvarene, jer od njihovog djelovanja u interesu naroda narod nije imao puno koristi? Pa se narod okreće švindlerima, a etablirana politika onda zvoni na uzbunu. Pri tomu etablirane elite nemaju odgovor: zbunjene i prisiljene da vode istu politiku na vlasti i u opoziciji, postaju neuvjerljive. Nemaju alternativu, već se prilagođavaju novonastalom stanju. Znači održavanja statusa quo, koji vodi tzv. stabilokraciji.

Ovdje je od interesa slučaj norveškog populizma. Manje je poznato da u Norveškoj postoji uspješna populistička struja/pokret/partija još od 
POLITIČKE PERSPEKTIVE

ČLANCI I STUDIJE

1970-ih. Začetnik je desni političar Anders Lange, čiji se program svodio na dvije točke: smanjenje poreza i pojeftinjenje alkohola, čime je sebi privukao klijente gornjih slojeva i radničke klase. Novi vođa Karl Ivar Hagen 1990-ih stvorio je čvrstu partijsku organizaciju i među svoje glasače uključio mladež, žene, kršćanske fundamentaliste uplašene islamskim imigrantima, protivnike države socijalnog staranja, sve one koji ne pripadaju tradicionalnim elitama. Vlastiti interes i egoizam zamijenio je tradicionalne solidarističke socijaldemokratske vrijednosti. Mislim da je taj populizam paradigma novog kameleonskog populizma, koji ilustrira savez donjih i gornjih slojeva koji naizgled dijele zajedničke muke, ali jednih je više, drugih manje, pri čemu malobrojniji profitiraju zbog demokracije, ali brojniji pate zbog interesa oligarhije. Možda će alkohol pojeftiniti, ali će se alkoholičari moći jeftinije napijati da bi zaboravili ono što su im oligarsi priskrbili da glasaju za njih. Upravo bi populistička politika Hagenove Napredne stranke najžešće pogodila deprivilegirani dio naroda, čijim se zaštitnikom lažno predstavlja. Druge partije nisu na nacionalnoj razini pokazale sposobnost da svoju politiku prezentiraju na razumljiv način. Napredna partija (sad u koalicionoj vladi s konzervativcima) živi od slabosti postojećih partija, a procesa formiranja volje odozdo prema gore nema (Einhart 2003).

Dijagnoza je postavljena. A kako odrediti terapiju, tko će biti doktori na terenu, ja ne znam. Želim otvoriti pitanja, odgovora nemam. Prije donošenja konačnih zaključaka, ako su takvi uopće mogući glede jedne fluidne protejske pojave poput modernog populizma, nužno je obaviti pripremne radnje: čišćenje pojma od naplavina populističke upotrebe populizma. Nužno je ustanoviti komponente koje su svojstvene modernoj demokraciji općenito i usredotočiti se na konkretne pojavne forme u konkretnim kontekstima s pogledom na genezu svakog populizma. To znači krenuti odozdo.

\section{LITERATURA}

Bakić, Jovo. 2013. „Populizam ili demagogija u političkom životu Srbije?“ U Mladen Lazić i Slobodan Cvejić (ur.). Promene osnovnih struktura društva Srbije u periodu ubrzane transformacije. Beograd: ISI i Čigoja.

Barsamian, David. 2017. Noam Chomski - intervju. Peščanik net 10. 10. 2017. https:// pescanik.net/noam-chomsky-intervju/ Pristupljeno 5. studenoga 2017.

Bogdanović, Mira. 2015. The Rift in the Praxis Group: Between Nationalism and Liberalism. Critique, 43 (3-4): 461-483. http://dx.doi.org/10.1080/03017605.20 15.1099850.

Bogdanović, Mira. 2016. Elitistički pasijans. Povijesni revizionizam Latinke Perović - O nemislicama, nedomislicama, dvomislicama i besmislicama. Zemun: Mostart. 


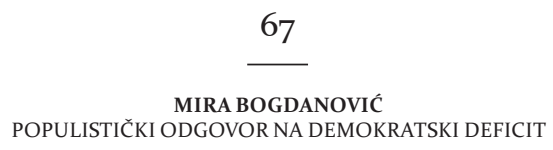

Eigenmann, D. 2017. Jakob Augstein - intervju. Peščanik. net 11. 5. 2017. https://pescanik.net/jakob-augstein-intervju/ Pristupljeno 5. studentoga 2017.

Ionescu Ghįta and Gellner Ernest (eds.). 1970. Populism: Its Meanings and National Characteristics. London: Weidenfeld and Nicholson.

Janković, Ivan. 1985. Smrt u prisustvu vlasti: Smrtna kazna u Jugoslaviji i svetu. Beograd: Istraživačko-izdavački centar SSO Srbije.

Lorenz, Einhart. 2003. „Rechtspopulismus in Norwegen: Carl Ivar Hagen und die Fortschrittspartei”. In Hrg. Nikolaus Werz. Populismus - Populisten in Übersee und Europa, Wiesbaden GmbH: Springer Fachmedien, pp. 195-205.

Mudde, Cas and Kaltwasser Rovira, Cristóbal. 2017. Populism - A Very Short Introduction. Oxford: Oxford University Press.

Nikolić, Miloš. 2017. „Stvarnost hroničnog populizma - O zloupotrebi naroda i potrebi utvrđivanja uzroka populizma u Srbiji". U Srđan Cvetković i dr. Zloupotreba naroda: Priroda populizma u Srbiji. Beograd: Libertarijanski klub Libek.

Popov, Nebojša. 1989. Contra fatum: Slučaj grupe profesora Filozofskog fakulteta u Beogradu 1968-1988. Beograd: Mladost.

Popov, Nebojša. 1993. „Srpski populizam od marginalne do dominantne pojave”. Beograd. Vreme Broj 135. www.vreme.com/cms/view.php?id=1112603 Pristupljeno 5. studenoga 2017.

Stojanović, Dubravka. 2017. Srbija - avangarda populizma. Peščanik.net 27. 4. 2017. http://pescanik.net/srbija-avangarda-populizma Pristupljeno 5. studenoga 2017 .

\section{SUMMARY}

\section{Populist Answer To The Democratic Deficit}

The present populism research follows two major lines of inquiry: one is top down, the other bottom up. The first one focuses on distilled abstract traits of the phenomenon with an emphasis on common features. The second one concentrates on distinct features of populisms country wise in historical perspective. The first one maintains an undisguised liberal ideological bias and neglects populism as an (il)legitimate offspring of liberal democracy. The author argues that the second approach yields a deeper insight into the nature of contemporary populism as a by-product of the breakdown of traditional party politics.

KEY WORDS: populism sui generis, political party cartels, nondemocratic liberalism, democracy. 